\title{
Methodological approaches to the development of criteria-based assessment of educational results
}

\author{
Tatyana Orekhova $^{1 *}$, Tatiana Neretina $^{1}$, Natalya Ustselemova $^{2}$, Tamara Krujilina ${ }^{1}$, and \\ Anastasia Goncharova ${ }^{3}$ \\ ${ }^{1}$ Nosov Magnitogorsk State Technical University, Institute for the Humanities, Department of \\ Pedagogical Education and Documentation, Magnitogorsk, Russia \\ ${ }^{2}$ Nosov Magnitogorsk State Technical University, Faculty of Physical Culture and Sports Excellence, \\ Department of Physical Culture, Magnitogorsk, Russia \\ ${ }^{3}$ Nosov Magnitogorsk State Technical University, Civil Engineering, Architecture and Arts Institute, \\ Department of Architecture, Magnitogorsk, Russia
}

\begin{abstract}
The article presents the authors' experience in developing and applying criteria for assessing the results of the educational activities of students in the system of contemporary education. The necessity and expediency of its implementation are justified by the actual difficulty of objective assessment of the quality of educational results; reduction of the motivating function of the five-point assessment; as well as natural and personal uniqueness of each student as a subject of educational activity. The analysis of domestic and foreign studies on the problem of criteriabased assessment of learning results in the system of general and higher education shows that despite various approaches to the criteria-based assessment of learning results, the methodology of its development is not sufficiently covered in pedagogical science and practice. The present research aims to develop a pedagogically appropriate methodology for constructing a criteria-based assessment of the results of students' educational activities. This methodology includes several interrelated actions: establishing three levels of students' mastering of the content of each discipline; developing quantitative indicators and qualitative characteristics of each level; ensuring methodological development of requirements for each task; bringing to the attention of students the content of each level of mastering of the main educational program. An important condition is the ability to repeatedly correct each task to bring it to the highest possible level of perfection. The leading methodological position is given to the idea of the human's inherent desire for success and to be the first. As the results of the conducted study show, the implementation of the proposed methodology naturally leads to an enhancement of the education quality, which is reliable proof of its scientific novelty.
\end{abstract}

Keywords: quality of education, criteria-based assessment, methodology, students.

\footnotetext{
*Corresponding author: orehovna49@mail.ru
} 


\section{Introduction}

The relevance of the problem of criteria-based assessment of educational results is determined by several objective and subjective prerequisites. First of all, this is a universally recognized difficulty in objectively assessing students' educational achievements, which is explained by the uniqueness of each of them as a subject and carrier of education, as well as the subjectivity of pedagogical assessment due to the personal attitude of the teacher to students, which is quite understandable.

Mastering of the educational content established in the principle educational program (PEP) depends on a variety of objective factors, including the natural potential of physical, mental, and intellectual development inherited by the individual; spontaneous and systemic educational impact on the growing person of the external environment in the form of an unorganized and organized environment; motivation of the student to acquire knowledge and master skills; the creative nature of a person, which reveals itself in its conscious and unconscious manifestations, as well as many other natural and social factors that together determine the idiosyncratical uniqueness, individuality of each person, which in principle cannot be taken into account in the context of collective learning.

Today it becomes clear that during numerous reformation transformations of the national education, including its transformation from the cultural sector to the service sector, a five-point assessment of learning results adopted in the Soviet school has become four-point, namely, three positive ratings (excellent, good, and satisfactory) and one unsatisfactory ascertaining in practice not so much the lack or insufficiency of knowledge of the student but everything that has an indirect relationship to education. In this regard, contemporary assessment is gradually losing its motivational and regulatory functions.

This implies the need to formalize the assessment of learning results, which is stated in the current Federal State Educational Standards of general education in the form of a criteria-based assessment of the students' results of educational activities, the effectiveness of teachers and educational institutions, as well as the functioning of the education system in general. Hence, one of the important research tasks is to determine the general methodological bases for developing a criteria-based assessment of educational results.

In understanding the essence of the criteria-based assessment, the authors proceed from the definition of the criterion (from the Greek, word $\kappa \rho \imath \eta^{\prime} \rho \imath o v$ is a means for judgment, decision) as a measure, a sign, a means of verification, an essential distinguishing feature of the validity of a certain statement, which is used to assess the truth of knowledge. The concept of the criterion is used in various sciences and involves a detailed description of the requirements and conditions that meet a certain standard and provide a quantitative and qualitative basis for the assessment-based conclusion.

Based on the above, the criteria-based assessment of educational results is understood as a pedagogically appropriate means of establishing correspondence between the set educational requirements and the level of their implementation by students as acting and learning subjects. With this understanding of the essence of the criteria-based assessment, its objectivity is determined by three determinants, namely, determining the levels of students' mastering of the content of academic disciplines; quantitative and qualitative characteristics of each level; and algorithmization of all types of educational activities of students, which naturally leads to an increase in the quality of educational results.

Thus, the novelty of the research lies in the proposed methodology for developing a criteria-based assessment of students' educational achievements as a factor of improving the quality of education.

When reasoning, the authors proceed from the assumption that the requirements for mastering the content of education that is developed in detail and technologically brought to the minds of students are a means of motivating them to achieve the maximum possible 
individual results, which naturally contributes to improving the quality of education. Hence, the purpose of the study is to develop a pedagogically appropriate methodology for constructing a criteria-based assessment of various results of students' educational activities.

The goal is achieved by solving several tasks: 1) determining the content of the concept of criteria-based assessment as a factor in improving the quality of education; 2) describing the methodology for developing a criteria-based assessment of the quality of educational tasks of various types; 3 ) testing the proposed methodology in the course of the training of students of a higher education institution.

\section{Methods}

When determining the methodological grounds for developing criteria-based assessment of the students' educational results, the authors proceeded from the following methodological provisions:

- the criterion is a formalized indicator of students' education,

- the form of presenting criteria to students represents a list of requirements for educational results (knowledge and skills),

- knowledge is a generalized characteristic of the intellectual status of the student at each stage of education,

- students' awareness of the requirements for assessing the completed task is a motivating factor for improving the quality of education since every person has a natural desire to be the first.

The basic methods include analysis to identify trends in the criteria-based assessment of students' educational achievements in contemporary pedagogical practice; modeling as a method of meaningful design of educational tasks; intellectual experiment as a way to think through a real operation which can be implemented practically; pedagogical experiment aimed at verifying the reliability of the hypothesis; a method for measuring students' academic performance through a ratio scale that allows determining the number of correctly completed tasks and mistakes made.

\section{Results}

The first stage of methodological development of criteria for assessing the results of educational activities is distinguishing the levels of students' development of the content of each academic discipline. The determining factor is the principle of optimality, according to which a list is drawn up for each topic: 1) the necessary knowledge, whose presence allows considering the level of mastering of the content of PEP by students to be sufficient; 2) skills corresponding to this knowledge with a qualitative characteristic of the signs of each skill.

At the second stage, a quantitative range is set for the scope of mastered content for each level. Two approaches can be used to develop a rating scale: one allows for the possibility of negative assessment, and the other assumes the unconditional presence of an acceptable level.

In the first approach, a passing score is set corresponding to $50 \%$ of the mastered course content, while mastering less than $50 \%$ of the content is not assessed positively. A high level of mastering course content corresponds to a range from 85 to $100 \%$, an average from 67 to $84 \%$, and a low - from 50 to $66 \%$. The second approach is based on a scale according to which up to $25 \%$ of the acquired material corresponds to a low level of mastering course content, from 26 to $74 \%$ - to average level, and from 75 to $100 \%$ - to 
high level. Level assessments in points are brought to the attention of students and set according to the knowledge in each topic or task, and the corresponding skills.

At the third stage, requirements are developed for each task, brought to the attention of students, and serve as the basis for criteria-based assessment. At that, the more detailed the requirements for quantitative and qualitative parameters are developed, the higher is the quality of the work performed and, accordingly, the level of mastering the educational content. Thus, the following methodological aspects of the criteria-based assessment of educational tasks can be distinguished:

- clarity of the task goal formulation (explaining and justifying the significance of certain knowledge for the training and professional activity of the student);

- the availability of methodological recommendations for performing the task (step-bystep instruction to the task executing procedure, and a clear set of requirements for the technical design of the task);

- the availability of a sample or example of the completed task;

- preliminary communication to the students of the indicators used to assess the quality of completed tasks;

- checking the task and providing the comments of each nonconformance to requirements;

- allowing the students to resubmit the task to be checked aimed at upgrading it to a required quality level;

- making the final assessment of the completed task, if it was repeatedly submitted, as an objective assessment of the quality of the student's educational achievements.

The results of implementing the developed method into the practice of preparing students indicate its high efficiency that is evidenced by indicators, such as academic performance (almost $100 \%$ of Master students and about $40 \%$ of Bachelor students receive diplomas with honors) and the level of uniqueness of their graduation papers, which on average varies between 70 and $95 \%$.

\section{Discussion}

The problem of developing and implementing criteria-based assessment of various aspects of education is relevant for education in different countries, as evidenced by the analysis of domestic and foreign studies presented in the works of Zh.A. Abekova, A.B. Oralbaev, M. Berdalieva, Zh.K. Izbasarova [1]; M.A. Askarova [2]; L.A. Zhuravleva, I.V. Kovtyukh, S.V. Pyshnograyev [3]; M.I. Kovel, G.V. Glinkina [4]; A.A. Krasnoborova [5]; Ye.E. Kriventsova, N.A. Gunina [6]; V. Kh. Mansurova [7]; S.K. Murtazoeva [8]; M.A. Nurgaliyeva [9]; B.D. Nygmetova, N. S. Sarbasov [10]; Yu.A. Pavperova [11]; Ya.D. Pryanichnikova [12]; N.M. Stukalenko, S.V. Pukhlyakova [13]; I.A. Shcherbakova [14]; Y. Ai [15]; B. Avota [16]; A.B. Barcelona [17]; K. Berzina, I. Zicmane, J. Kuckovskis [18]; A.M. Bozieva [19]; F. Kahkoun, S.A. Ghannouchi [20]; N. Sakharchuk [21]; K. Thorpe, P, Rankin, T. Beatton, I. Siraj, S. Staton [22]; C. Schneijderberg, and I. Steinhardt [23].

Among these studies, the experience of involving students in the development of criteria for assessing educational results and forming their ability to independently assess their educational activities is of particular interest that naturally increases their responsibility for results and the level of self-esteem [6, 8, 13, 16, 18]. Due to updating the content of education in the Republic of Kazakhstan, scholars and practitioner teachers developed methods of criteria-based assessment of learning results of students $[1,7,9,10]$. At that, almost all authors associate the criteria-based assessment of students' academic achievements with the quality management of education $[19,21,22]$. 
The conducted analysis suggests that a theory of the criteria-based quality assessment of educational results is currently being created, which includes working out the conceptual framework, defining the principles and functions, methods and technologies of criteriabased assessment, and testing ways to implement criteria-based assessment in the educational practice of educational institutions at different levels. However, the methodological aspects of developing a criteria-based assessment of educational results are not sufficiently uncovered in the presented studies.

\section{Conclusion}

The obtained results allow drawing the following conclusions:

- criteria-based assessment of students, developed according to the proposed methodology, is the means to remote control students' independent work;

- detailed requirements for the learning results of students definitely improve education quality;

- the presence of comprehensive understanding of the content of each level among students acts as a motivational factor that stimulates their cognitive activity.

\section{References}

1. Zh.A. Abekova, A.B. Oralbaev, M. Berdaliyeva, Zh.K. Izbasarova, International Journal of Experimental Education, 2(2), 215-218 (2016). Accessed on: December 20, 2020. [Online]. Available: http://www.expeducation.ru/ru/article/view?id=9559

2. M.A. Askarova, Molodoy uchenyy, 20.1(79.1), 34-36 (2014). Accessed on: December 20, 2020. [Online]. Available: https://moluch.ru/archive/79/14071/

3. L.A. Zhuravleva, I.V. Kovtyukh, S.V. Pyshnograyev, Shkolnaya pedagogika, 2(5), 3-6 (2016). Accessed on: December 20, 2020. [Online]. Available: https://moluch.ru/th/2/archive/27/854/

4. M.I. Kovel, G.V. Glinkina, Nauka i shkola, 5, 84-95 (2018)

5. A.A. Krasnoborova, Obucheniye, testirovaniye i otsenka, 10, 73-77 (2010)

6. Ye.E. Kriventsova, N.A. Gunina, Questions of modern science and practice. University named after V.I. Vernadsky, 1(59), 159-164 (2016). https://doi.org/10.17277/voprosy.2016.01.pp.159-164

7. V.Kh. Mansurova, Pedagogicheskaya nauka i praktika, 4(18), $73-76$ (2017)

8. S.K. Murtazoeva, European Research, 7(30), 45-48 (2017)

9. M.A. Nurgaliyeva, Pedagogicheskaya nauka i praktika, 1(19), 115-117 (2018)

10. B.D. Nygmetova, N.S. Sarbasov, Sankt-Peterburgskiy obrazovatelnyy vestnik, 2(6), 28-32 (2017)

11. Yu.A. Pavperova, Pedagogicheskaya nauka i praktika, 2(16), 33-36 (2017)

12. Ya.D. Pryanichnikova, Bulletin on Pedagogy and Psychology of Southern Siberia, 1, 83-92 (2017)

13. N.M. Stukalenko, S.V. Pukhlyakova, Sovremennyye naukoyemkiye tekhnologii, 12-1, 74-75 (2014)

14. I.A. Shcherbakova, K voprosu obespecheniya kachestva professional 'noy podgotovki studentov kolledzha, in Actual problems of modern general and vocational education: a collection of articles based on the materials of the III All-Russian correspondence scientific and practical conference with international participation, 28-34 
(Magnitogorsk State Technical University named after G. I. Nosov, Magnitogorsk, 2018)

15. Y. Ai, Study on Teaching Quality Evaluation Criteria of General Music Education Course in Colleges and Universities, in 2nd International Conference on Arts, Design and Contemporary Education (ICADCE). Proceedings of the 2016 International Conference on Arts, Design and Contemporary Education Series: Advances in Social Science Education and Humanities Research, 23-25 May 2016, Moscow, Russia (2016)

16. B. Avota, Assessment of distance learning quality criteria for continuing education of medical practitioners, in International Scientific Conference on Society, Integration, Education, Rezekne Acad Technologies, 25-26 May 2018, Rezekne, Latvia (2018)

17. A.B. Barcelona, International Journal of Evaluation and Research in Education, 9(3), 517-523 (2020). https://doi.org/10.11591/ijere.v9i3.20626

18. K. Berzina, I. Zicmane, J. Kuckovskis, Self-assessment as a key criterion for increase of quality of higher education in Modern conditions, in International Conference on Electromechanical and Power Systems (SIELMEN), 11-13 October 2017, Lasi, Romania (2017). https://doi.org/10.1109/SIELMEN.2017.8123373

19. Bozieva, A. M. Education Quality Criteria within the Competence Model of the Graduate, in International Conference on Quality Management, Transport and Information Security, Information Technologies (IT and QM and IS), 23-30 September 2017, Saint Petersburg, Russia (2017)

20. F. Kahkoun, S.A. Ghannouchi, Evaluating the Quality of Business Process Models Based on Measures and Criteria in Higher Education: Developing a Framework for Continuous Quality Improvement, in 16th International Conference on Intelligent Systems Design and Applications (ISDA), 16-18 December 2016, Porto, Portugal (2016)

21. N. Sakharchuk, Criteria system of quality of education: methodological and practical aspects of establishment, in International Technology, Education and Development Conference (INTED), 11-13 April 2019, Valencia, Spain (2019)

22. K. Thorpe, P. Rankin, T. Beatton, S. Houen, M. Sandi, I. Siraj, S. Staton, Early Childhood Research Quarterly, 53, 274-286 (2020). https://doi.org/10.1016/j.ecresq.2020.05.003

23. C. Schneijderber, I. Steinhardt, High Educ Policy, 32(1), 5-28 (2019). https://doi.org/10.1057/s41307-018-0111-y 